\title{
Suspension of Egg Hatching Caused by High Humidity and Submergence in Spider Mites.( main article )
}

\author{
$\operatorname{AUTHOR}(\mathrm{S})$ :
}

Ubara, Masashi; Osakabe, Masahiro

\section{CITATION:}

Ubara, Masashi ... [et al]. Suspension of Egg Hatching Caused by High Humidity and Submergence in Spider Mites.. Environmental entomology 2015, 44(4): 1210-1219

\section{ISSUE DATE:}

2015-08

URL:

http://hdl.handle.net/2433/203045

\section{RIGHT:}

This is a pre-copyedited, author-produced PDF of an article accepted for publication in 'Environmental entomology' following peer review. The version of record [Ubara Masashi, Osakabe Masahiro. Suspension of Egg Hatching Caused by High Humidity and Submergence in Spider Mites. 44(4) 1210-1219.] is available online at:

http://ee oxfordjournals.org/content/44/4/1210.; All files will be made open to the public on 25 May 2016 in accordance with publisher's 'Terms and Conditions for Self-Archiving'.; この論文は出版社版でありません。引用の際には出版社版 をご確認ご利用ください。; This is not the published version. Please cite only the published version. 
1 Ubara and Osakabe: Egg hatching strategies of

2 spider mites

3

4 Journal of Environmental Entomology

5 Physiological Ecology

6

7

8

17

18

19

20

21

22

23 Masashi Ubara, Masahiro Osakabe ${ }^{1}$

24 Laboratory of Ecological Information, Graduate School of Agriculture, Kyoto University, Kyoto

25 606-8502, Japan
9 M. Osakabe

10 Laboratory of Ecological Information,

11 Graduate School of Agriculture, Kyoto

13 Kyoto 606-8502, Japan

14 Phone: 81-75-753-2267

15 Fax: 81-75-753-2267

16 E-mail: mhosaka@kais.kyoto-u.ac.jp
12 University

Suspension of egg hatching caused by high humidity and submergence in spider mites

26 


\section{ABSTRACT}

29 We tested the effects of high humidity and submergence on egg hatching of spider mites. In both

30 the high humidity and submergence treatments, many Tetranychus and Panonychus eggs did not

31 hatch until after the hatching peak of the lower humidity/unsubmerged controls. However, after

32 humidity decreased or water was drained, many eggs hatched within 1-3 h. This was observed

33 regardless of when high humidity or submergence treatments were implemented: either

34 immediately after oviposition or immediately before hatching was due. Normal eyespot formation

35 was observed in most eggs in the high humidity and submergence treatments, which indicates that

36 spider mite embryos develop even when eggs are underwater. Therefore, delays in hatching are not

37 caused by delayed embryonic development. A delay in hatching was always observed in

38 Panonychus citri but was more variable in Tetranychus urticae and Tetranychus kanzawai. The

39 high humidity and submergence treatments affected but did not suppress larval development in

40 these species. In contrast, many Oligonychus eggs died following the high humidity treatments. In

41 Tetranychus and Panonychus spider mites, suspension of egg hatching may mitigate the adverse

42 effects of rainfall.

KEY WARDS Delayed hatching, Embryonic development, Environmental adaptation, 


\section{Introduction}

The time required to develop and reproduce affects the fitness of organisms living under variable environments. For example, egg hatch timing affects the survival and development of larvae, and thus the population dynamics of insects (Pickford 1960; Moriyama and Numata 2006).

Spider mites (Acari, Tetranychidae) are small herbivorous arthropods and include economically important agricultural pests. Many live on the leaf surfaces of their host plants, where they are exposed to various environmental stresses such as desiccation (McEnroe 1961; Ferro and Chapman 1979), heat stress (Perring et al. 1984; Lu et al. 2014), and solar ultraviolet radiation (Sakai et al. 2012; Fukaya et al. 2013). Heavy rains such as during hurricanes and typhoons may also be important to spider mite population dynamics (Osakabe 1965; Boyne and Hain 1983; Ho 2000; Rêgo et al. 2013). However, Klubertanz et al. (1990) found that rainfall did not affect spider mite dynamics.

Females of the citrus red mite, Panonychus citri (McGregor), an upper leaf surface user, move from the upper to lower leaf surfaces during rainfall (Kato 1972). Additionally, the Kanzawa spider mite, Tetranychus kanzawai Kishida, suspend molting as quiescent deutonymphs if the air humidity is high [relative humidity $(\mathrm{RH}) \approx 100 \%$ ] and resume molting after the humidity decreases (Ikegami et al. 2000). Since quiescent deutonymph females can tolerate more water than adult females (cf. Osakabe 1967), this may be an adaptation to rain (Ikegami et al. 2000).

Studies have reported that under conditions of high humidity, spider mite eggs did not hatch (Kuenen 1946; Osakabe 1959; Bonato et al. 1995), the hatch rate decreased (Mori 1957; Boudreaux 1958; Ferro and Chapman 1979), or egg stages were prolonged (Mori 1957; Boyne and Hain 1983). In these previous studies, however, the authors sought to clarify the effects of 
70 continuous high humidity on egg development and hatching; the adaptive significance of these

71 phenomena remains unclear. If hatch timing can be regulated to avoid rain damage, larval survival

72 rates would increase, which would contribute to the population dynamics of spider mites.

73 Many plant-dwelling mites generally remain on lower leaf surfaces (Sudo and Osakabe 2011),

74 but some species such as Panonychus spp. inhabit both lower and upper leaf surfaces (Foot 1963;

75 Kato 1972; Osakabe et al. 2006; Fukaya et al. 2013). Rainfall likely more directly affects the

76 survival and dynamics of mites living on the upper leaf surfaces. Therefore, species of upper

77 surface users might be adapted to rain, while lower leaf surface users are not.

In this study, we tested the effects of temporal high humidity and submergence in water on

egg hatching using spider mites inhabiting both the upper and lower leaf surfaces. We also examined whether the high humidity and submergence treatments in egg stage decrease survival and development in subsequent juvenile stages, and the reproduction of females.

\section{Materials and Methods}

Tetranychus Species. A green form laboratory population of the two-spotted spider mite,

Tetranychus urticae Koch, was established from several different localities in Japan and cultured on potted kidney bean plants for at least 7 years. The red form of T. urticae was collected from carnations, Dianthus caryophyllus L. (Caryophyllaceae), in a greenhouse at the Nagano

89 Prefecture Vegetable and Ornamental Crops Experiment Station, Nagano, Nagano Prefecture, Japan $\left(36^{\circ} 35^{\prime} \mathrm{N}-138^{\circ} 13^{\prime} \mathrm{E}\right)$ in July, 2006. Tetranychus kanzawai and the bean spider mite,

91 Tetranychus ludeni Zacher, were collected from melons, Cucumis melo L. (Cucurbitaceae), in a 
92 greenhouse at the Shizuoka Prefectural Research Institute of Agriculture and Forestry, Iwata,

93 Shizuoka Prefecture, Japan $\left(34^{\circ} 43^{\prime} \mathrm{N}-137^{\circ} 50^{\prime} \mathrm{E}\right)$ in November 2010.

94 Panonychus Species. Panonychus citri was collected from satsuma mandarins, Citrus unshiu

95 Marc. (Rutaceae), in a citrus grove at the Citrus Research Division, Kuchinotsu, National

96 Agriculture and Food Organization Institute of Fruit Tree Science, Minamishimabara, Nagasaki

97 Prefecture, Japan $\left(32^{\circ} 36^{\prime} \mathrm{N}-130^{\circ} 11^{\prime} \mathrm{E}\right)$ in June, 2007. Panonychus osmanthi Ehara and Gotoh

98 was collected from fragrant olives, Osmanthus fragrans Lour. var. aurantiacus Makino

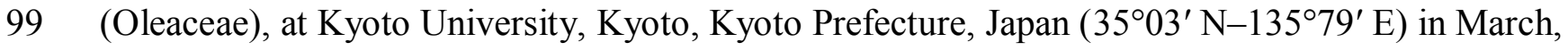

100 2011. Panonychus mori Yokoyama was collected from Japanese pears, Pyrus pyrifolia var. culta

101 Nakai (Rosaceae), in an orchard at the Horticultural Experiment Center, Tottori Prefectural

102 Agriculture and Forest Research Institute, Hokuei, Tottori Prefecture, Japan $\left(35^{\circ} 28^{\prime} \mathrm{N}-133^{\circ} 44^{\prime} \mathrm{E}\right)$

103 in July, 2012. Panonychus ulmi (Koch) was collected from apple trees, Malus domestica Borkh

104 (Rosaceae), in an orchard at the Akita Fruit-Tree Experiment Station, Yokote, Akita Prefecture,

105 Japan $\left(39^{\circ} 14^{\prime} \mathrm{N}-140^{\circ} 31^{\prime} \mathrm{E}\right)$ in July, 2012.

106 Oligonychus Species. Oligonychus amiensis Ehara and Gotoh and Oligonychus castaneae

107 Ehara and Gotoh were collected from Japanese stone oaks, Lithocarpus edulis (Makino) Nakai

108 (Fagaceae), and Japanese chestnuts, Castanea crenata Sieb. et Zucc. (Fagaceae), respectively, at

109 Kyoto University in July 2012. No males appeared in the O. amiensis population in reared

110 cultures. Many individuals of $O$. amiensis and $O$. castaneae inhabit upper leaf surfaces.

111 Rearing Conditions for Stock Cultures. Spider mites were reared on leaf disks of host

112 plants placed with the adaxial surface up on water-soaked cotton in Petri dishes (90 mm diameter

113 and $20 \mathrm{~mm}$ depth). The dishes were placed in a transparent plastic container $(350 \times 250 \times 50 \mathrm{~mm})$

114 whose lids (200 $\mathrm{mm}$ in diameter) were covered with fine polyester fiber mesh and kept in a 
115 laboratory at $25 \pm 2{ }^{\circ} \mathrm{C}$ and $50-70 \% \mathrm{RH}$, with a 16:8 h L:D light cycle (fluorescent lights were

116 turned on at 07:00 h and off at 23:00 h). All experiments were performed in the same laboratory.

117 All Tetranychus spp. and P. citri were kept on kidney bean leaf disks. Although kidney beans

118 are not the main hosts of $P$. citri, these mites can develop and reproduce normally on leguminous

119 plants (Ashihara, 1987; Fukaya et al., 2013). Panonychus osmanthi, P. mori and P. ulmi were

120 reared on leaves of Japanese pears, which are a suitable host plants for P. osmanthi (Kitashima

121 and Gotoh, 1995). Oligonychus amiensis and O. castaneae were reared on the leaves of Japanese

122 stone oak and Japanese chestnut, respectively.

123 Effects of High Humidity on Egg Hatch Timing. We used three types of treatments to

124 evaluate the effects of high humidity on egg hatch timing: high humidity after oviposition (within

$12524 \mathrm{~h}$ ) to hatching [Experiment (Exp)-1], high humidity immediately before hatching was due

126 (Exp-2), and high humidity immediately after oviposition and continuing after hatching was due

127 (Exp-3). We used all species of spider mites for Exp-1; T. urticae green form, T. urticae red form,

128 T. kanzawai, T. ludeni, and P. citri for Exp-2; and T. urticae green form, T. kanzawai, and P. citri 129 for Exp-3.

130 Two leaf squares $(20 \times 20 \mathrm{~mm})$ of the same plants as those mites were reared on were placed

131 on water-soaked cotton in Petri dishes. We introduced 5 Tetranychus, 15 Panonychus, or 20

132 Oligonychus adult females (3-5 days old) to each leaf square. After $24 \mathrm{~h}$, females were removed

133 (day 0) and eggs were counted. We used two Petri dishes per batch and performed three times in

134 Exp-1 and Exp-2. Whereas, we used five Petri dishes and performed once in Exp-3.

135 We covered one of the two Petri dishes in Exp-1 and four of the five Petri dishes in Exp-3

136 with a transparent plastic lid (high humidity treatments) and left the others open (control) at day 0.

137 In Exp-2, Petri dishes in the high humidity treatments were covered with lids on days 2 and 4 for 
138 Tetranychus spp. and P. citri, respectively. These were the days before expected hatch in the

139 controls. In the high humidity treatment, the RH immediately increased and reached $>95 \%$ within

$14010 \mathrm{~min}$ of the dishes being covered. The temperature was slightly higher in the high humidity than

141 in the control treatment as a result of closing the lid (Table 1).

142 To avoid attachment of water droplets on eggs in the high humidity treatment, water droplets

143 on the leaves and lid were removed using fine point brushes and tissue paper. This was carried out 144 within $30 \mathrm{~s}$ once daily.

145 We observed the status of the eggs every day and recorded the number of hatched eggs. On 146 the day after $>90 \%$ of the eggs hatched in the control treatments (days 5, 7, and 8 for Tetranychus, 147 Panonychus, and Oligonychus spp., respectively), we checked the development of eyespots in the 148 remaining eggs in the high humidity treatments. In Exp-1 and Exp-2, we removed the lids of Petri 149 dishes to decrease moisture. We recorded the number of eggs hatched just after lid removal and 1, 1503,24 , and $48 \mathrm{~h}$ later. No eggs hatched later than $48 \mathrm{~h}$. In Exp-3, we never opened the lids in the 151 high humidity treatment and observed hatching once a day until day 10. after oviposition to hatching (Exp-4) and submergence immediately before hatching (Exp-5) was due. We used T. urticae green form and P. citri for this experiment. transparent plastic case $(120 \times 120 \times 30 \mathrm{~mm})$. One-half (petiole side) of a kidney bean primary leaf was placed on the cotton, and the other half was extended on the bottom and covered with wet paper towels having a square hole $(20 \times 20 \mathrm{~mm}$; Fig. 1). We prepared eight plastic cases (four 
161 experiments were performed three times.

162 We introduced 5 T. urticae or 15 P. citri adult females to the inside of the square hole of 163 paper towel on each leaf. We then removed the mites after $24 \mathrm{~h}$ and counted eggs (day 0 ). To

164 submerge the eggs, we poured distilled water into the two cases (Fig.1) on day 0 for Exp-4 and on 165 day 2 and day 4 (the days of expected hatch for control individuals) for T. urticae and P. citri, 166 respectively, for Exp-5. By only submerging half of the leaf, leaves were able to be kept fresh 167 during the experiment. The remaining two cases were used as controls.

168 On the day after $90 \%$ of the eggs hatched in the control treatments, we checked the 169 development of eyespots in the remaining eggs and drained water (on days 5 and 7 for T. urticae 170 and $P$. citri, respectively). We recorded the number of eggs hatched immediately after water was 171 drained and 3, 24, and $48 \mathrm{~h}$ later. No eggs hatched later than $48 \mathrm{~h}$.

172 We also observed egg hatching after submergence using stereoscopic microscope with a 173 CCD camera (ARTCAM-274KY-WOM, ARTRAY, Tokyo). We stuck a piece of Parafilm $(30 \times$ $17440 \mathrm{~mm}$ ) on the inside bottom of two Petri dishes. The Parafilm was covered with wet paper towel 175 having a square hole $(20 \times 20 \mathrm{~mm})$. Then, we introduced 5 T. urticae (or 15 P. citri) adult females 176 to the inside of the square hole of paper towel on each Parafilm. We then removed the mites after $17724 \mathrm{~h}$ and poured distilled water into one of the two Petri dishes, and the remaining one was used 178 as a control. On the day after $90 \%$ of the eggs hatched in the control, we drained water and began 179 to photography at 2-min intervals until almost eggs hatched.

180 Effects of High Humidity and Submergence on Juvenile Development. We investigated 181 the development of T. urticae green form and P. citri larvae hatched from eggs exposed to high 182 humidity or submergence from immediately after oviposition to hatching (Exp-6). For this 183 experiment, we prepared two Petri dishes for each of three treatments: high humidity, 
184 submergence, and control (on leaf squares in open Petri dishes). We randomly chose 20 larvae 185 and individually transferred them to kidney bean leaf squares $(10 \times 10 \mathrm{~mm})$ on water-soaked 186 cotton in Petri dishes (20 leaf squares per dish). We then assessed the time required for mites to 187 emerge as adults. Virgin adult females were individually transferred to new leaf squares $(10 \times 10$ $188 \mathrm{~mm}$ ), and we recorded the numbers of eggs for the first 5 oviposition days. If a female died during

189 this time, it was excluded from data analysis. Larvae that remained on original leaves were 190 observed for developmental success (to adulthood) and sex ratio. These observations were 191 performed three times.

Statistical Analyses. We used R v. 2.15.2 (R Core Development Team 2012) for statistical analysis except $R \times C$ tests of independence. Hatch rates in high humidity or submergence treatments and controls in Exp-1, 2, 4, and 5 were tested using Fisher's exact test "fisher.test"

195 function in R. Differences in the ratios of eggs that developed eyespots and successfully adjusted 196 hatching (hatched after humidity decreased or water was drained) in Exp-1, 2, 4, and 5;

197 differences in hatch rate in Exp-3; and differences in developmental success and sex ratio in Exp1986 were analyzed with $R \times C$ tests of independence using $G$-tests ( $G$-values were corrected using 199 Williams's correction: $\left.G_{\text {adj }}\right)$, following unplanned tests of homogeneity $\left(G_{\mathrm{H}}\right)$ of treatments for all 200 possible sets of data (Sokal and Rohlf 2000). These analyses were performed using the sum total 201 of eggs or individuals over all Petri dishes used in each experiment. analysis of variance (ANOVA; “aov” function in R) followed by a Tukey’s HSD post hoc test 204 (“TukeyHSD” function in R) after Bartlett's test for homogeneity of variances ("bartlett.test" 205 function in R). The effects of treatments on egg production in Exp-6 were evaluated using 206 generalized linear models (GLMs with Poisson error). We treated each individual as a sample unit 
207 in these experiments.

\section{Results}

212 of the eggs of all species in the high humidity treatments (Table 2). Nevertheless, we observed a

213 negative effect of high humidity on the egg hatch rate in all species, especially $P$. citri, for which

214 no eggs hatched (Fig. 2). In contrast, with the exception of $O$. castaneae and $O$. amiensis eggs,

215 many eggs hatched after humidity was decreased. In Tetranychus spp. and P. citri, many eggs

216 hatched within $1 \mathrm{~h}$ of humidity decreasing (Fig. 2). Weaker but similar trends were observed in the 217 remaining three Panonychus spp.

218 The hatch rate in the high humidity treatments was $>84.4 \%$ for four Tetranychus spp., P. citri, and $P$. mori. However, except in T. kanzawai (Fisher's exact test, $P=1$ ), the hatch rate was still

220 lower than for the control (Table 2). The hatch rate decreased to 69.2 and $58.4 \%$ for P. osmanthi

221 and P. ulmi, respectively, and greater negative effects were observed in Oligonychus spp. (Table 2, 222 Fig. 2). Hatch rate after humidity decreasing was greatest for T. kanzawai and P. citri, followed by 223 T. urticae green and red forms, T. ludeni, and P. mori (Table 2).

224 Negative effects and suspension of egg hatch were also observed in the high humidity 225 treatment in Exp-2 (Fig. 3). Panonychus citri eggs did not hatch before the humidity was 226 decreased. A decrease in the hatch rate was observed in three species in the high humidity 227 treatment but not in T. urticae red form and T. kanzawai (Fisher's exact test, $P=0.419$ and 0.6626 , 
228 respectively; Table 3 ). The highest hatch rate after humidity decreasing was observed in $P$. citri,

229 and the most unsuccessful in T. kanzawai, in contrast to the results of Exp-1 (Table 3).

230 The hatch rate in Exp-3 was greatest in T. kanzawai $(96.0 \%)$, followed by T. urticae green

231 form (73.2\%), and was lowest in P. citri $\left(7.3 \%\right.$; $G$-test, d.f. $=2, G_{\text {adj }}=687.5413, P<0.001$; Fig. 4).

232 Tetranychus kanzawai tended to complete hatching earlier than T. urticae in Ex-1 and 2. In Exp-3,

233 the hatch rate was significantly greater in $T$. kanzawai than in $T$. urticae $\left(G_{\mathrm{H}}\right.$, d.f. $=2, G_{\text {adj }}=$

$23466.99835, P<0.001)$. Hatching was completed by day 7 in T. kanzawai and day 8 in T. urticae. In

235 contrast, the hatch rate of $P$. citri was significantly lower than that of $T$. urticae $\left(G_{\mathrm{H}}\right.$, d.f. $=2, G_{\mathrm{adj}}$

$236=425.9087, P<0.001)$.

Effects of Submergence on Egg Hatch Timing. Although T. urticae green form and P. citri eggs were submerged in water from immediately after oviposition to hatching in Exp-4, eyespots developed in most eggs (Table 4a). The hatch rate was lower than in the control treatment but still high; $94.2 \%$ of $T$. urticae eggs hatched, but a substantial number hatched in water and drowned

241 (Fig. 5a). In contrast, although the hatch rate of $P$. citri eggs (78.8\%) was lower than that of $T$.

242 urticae eggs, most hatched after water was drained (Fig. 5a). Consequently, the hatch rate after

243 humidity decreasing was not significantly different between these species ( $G$-test, d.f. $=1, G_{\text {adj }}=$ $244 \quad 0.7445, P>0.05 ;$ Table 4a).

245 Egg hatching was also suspended by the submergence treatments implemented immediately 246 before hatching day was due (Exp-5; Fig. 5b). Submergence affected the hatch rates of eggs of 247 both $T$. urticae and P. citri (Table 4b). Although the hatch rate was higher in T. urticae (94.1\%) 248 than in P. citri (84.0\%), the hatch rate after humidity decreasing was not significantly different 249 between these species $\left(G\right.$-test, d.f. $=1, G_{\text {adj }}=2.841845, P>0.05$; Table 4 b $)$.

250 Embryos of T. urticae (Supp. Video_S1) and P. citri (Supp. Video_S2) rotated $\sim 360^{\circ}$ 
251 immediately before hatching as shown in the animation, after which the shells opened and the

252 eggs hatched. Dorsal setae appeared along the line of rotation, suggesting that egg shells were cut 253 during the rotation.

254 Effects of High Humidity and Submergence on Juvenile Development. Developmental

255 success after submergence treatment (86-88\%) was lower than in the controls (94-96\%), but not

256 significantly different from development after high humidity (89-94\%; Exp-6; Table 5). No

257 statistical significance was detected between development in the high humidity treatment and the 258 control.

259 No significant differences were observed between treatments and controls in sex ratio, 260 developmental duration, and egg production, except in the developmental duration of T. urticae 261 females. The development of $T$. urticae females was slightly but significantly delayed in 262 comparison to that of control individuals. Similar trends were observed in both sexes of P. citri.

263 Consequently, treatments mainly affected developmental success and duration.

\section{Discussion}

Submergence in water is frequently a fatal event for terrestrial animals, at least partially due to oxygen deficits. For small spider mites, submergence can be caused even by a drop of rain, especially in upper leaf surface user such as P. citri. Spider mites are also intolerant of anoxia conditions (died out within $2 \mathrm{~h}$ ), although eggs survive slightly longer than other developmental 271 stages (Putman 1968). Nevertheless, the high rate of eyespot formation in T. urticae and P. citri 272 eggs indicates successful underwater embryonic development. Hatching of eggs in submergence 273 treatments was low, even when the majority of eggs hatched in the control treatments. Then, many 
274 eggs hatched immediately after water was drained. This response was reproduced when eggs of

275 Tetranychus and Panonychus spp. were under high humidity conditions, though the hatch rate

276 decreased in P. osmanthi and P. ulmi.

277 On the other hand, these responses were not observed in Oligonychus spp. eggs placed under

278 high humidity conditions. Why the responses of $O$. castaneae and O. amiensis eggs to decreased

279 humidity after high humidity differed from those of other species, and why many eggs died, are

280 unclear. Eggs of other Oligonychus spp., the spruce spider mite O. ununguis (Jacobi) and the

281 cotton red mite O. gossypii (Zacher), were also affected by high humidity (Boyne and Hain 1983;

282 Bonato et al. 1995), indicating that Oligonychus eggs may be generally susceptible to high

283 humidity.

284 Herne (1968) reported no effects of submersion in water for up to $48 \mathrm{~h}$ on the hatch rate of $P$.

$285 u l m i$ eggs. While, submerged eggs did not hatch under water even when submerged immediately

286 prior to normal hatching, while previously submerged eggs hatched later (Herne 1968). Our results

287 largely correspond with these observations. Many eggs hatched only after humidity was decreased

288 and water was drained, even if they had developed to the point of hatching before treatment were

289 implemented, indicating that delayed hatching in high humidity and water for Tetranychus and

290 Panonychus spp. is not caused by low embryonic developmental rates, but by the suspension of

291 hatching. This regulation is likely a result of the rotation behavior as the shell is cut just before

292 hatching. Eggs might monitor the surrounding environment through a respiratory system

293 consisting of shell perforation organs (the perforation cone) and a centripetal cone directly

294 connected to embryonic tissue (Dittrich 1971).

295 Boudreaux (1958) showed that although high humidity did not cause larval death directly, it

296 affected the juvenile development time in Tetranychus mites. In our experiments, the 
297 developmental success of individuals that experienced submergence during their egg stages

298 decreased and developmental time was slightly prolonged by submergence. However, these

299 negative effects are minor in comparison to those on larvae wetted by mist or reared under high

300 humidity conditions (Boudreaux 1958). Putman (1970) showed that P. ulmi larvae misted for 6-48

$301 \mathrm{~h}$ had $\sim 80 \%$ mortality, development was significantly delayed by a high humidity treatment, and

302 larvae were unable to survive at continuous high humidity. Therefore, the suspension of hatching

303 and passing damp and rainy conditions likely increases larval survival.

304 When eggs remained under high humidity, those of T. urticae and T. kanzawai gradually

305 hatched. In contrast, most $P$. citri eggs never hatched and eventually died. Leaves of citrus trees,

306 one of the major host plants of P. citri in a temperate zone (Osakabe 1987; Kitashima and Gotoh

307 1995), are water-repellent, which means that drops of water remain on leaves, especially on the

308 upper leaf surfaces, during rain. Since $P$. citri oviposits on both upper and lower leaf surfaces

309 (Jones and Parrella 1984; Fukaya et al. 2013), its eggs may be frequently submerged during rain.

310 However, its water repellency also means that citrus leaves dry quickly after rain. Cessation of

311 hatching may be adaptive for $P$. citri to survive rainfall events on the upper leaf surfaces of such

312 hosts.

313 In contrast, T. urticae and T. kanzawai prefer hairy leaves as habitats (Peters and Berry 1980;

314 Oku et al. 2006). Hairy leaves are soaked during rain, and water droplets are rarely formed.

315 Moreover, many eggs are laid on complicated webs produced by mothers among leaf hairs on the

316 lower leaf surfaces, which might function as shelter from the rain (Gerson 1985). Such habitats

317 may retain moisture longer compared to the habitat of $P$. citri. The high mortality of $P$. citri eggs

318 when they continuously experienced high humidity suggests that limits exist to elongate hatching,

319 after which hatching is unsuccessful. Generally, leaf stomata are concentrated on the lower leaf 
320 surfaces, resulting in higher humidity (Boulard et al. 2002). Thus, T. kanzawai and T. urticae are

321 likely to experience relatively high humidity more frequently than $P$. citri. If humidity remains

322 high, hatching might lessen the negative effects of rainfall. Duso et al. (2004) found that misty

323 water sprayed using fogging system suppressed T. urticae population on cucumber plants. They

324 suggested importance of contact with misty water for the reduction of mite population (Duso et al.

325 2004). In that, hatched larvae might be damaged from water rather than eggs because eggs do not

326 suspend hatching at lower than $90 \% \mathrm{RH}$.

327 We found suspension of egg hatching caused by high humidity and submergence, in

328 Panonychus and Tetranychus species, and not Oligonychus species. However, mechanisms of the

329 suspension and also resumption are largely unknown. We expect that spider mites can mitigate the 330 adverse effects of rainfall on juvenile stages on account of the suspension of egg hatching. To 331 elucidate this idea, further studies are required.

332

\section{Acknowledgments}

We thank Dr. S. Masui (Shizuoka Prefectural Research Institute of Agriculture and Forestry),

Mr. K. Seki (Nagano Prefecture Vegetable and Ornamental Crops Experiment Station), Mr. K.

337 Nakata (Tottori Prefectural Agriculture and Forest Research Institute), Mr. K. Funayama (Akita

338 Fruit-Tree Experiment Station) and Dr. H. Kishimoto (National Agriculture and Food

339 Organization Institute of Fruit Tree Science) for their kind help in collecting spider mites. 


\section{References Cited}

344 Ashihara, W. 1987. Infestation and reproduction of the citrus red mite, Panonychus citri

345 (McGregor) (Acarina: Tetranychidae) on leguminous plants. Appl. Entomol. Zool. 22: 512$346 \quad 518$.

347 Bonato, O., S. Mapangou-Divassa, and J. Gutierrez. 1995. Influence of relative humidity on 348 life-history parameters of Mononychellus progresivus and Oligonychus gossypii (Acari: 349 Tetranychidae). Environ. Entomol. 24: 841-845.

350 Boudreaux, H. B. 1958. The effect of relative humidity on egg-laying, hatching, and survival in 351 various spider mites. J. Insect Physiol. 2: 65-72.

352 Boulard, T., M. Mermier, J. Fargues, N. Smits, M. Rougier, and J. C. Roy. 2002. Tomato leaf 353 boundary layer climate: implications for microbiological whitefly control in greenhouses. Agr. $354 \quad$ Forest Meteorol. 110: 159-176.

355 Boyne, J. V., and F. P. Hain. 1983. Effects of constant temperature, relative humidity, and 356 simulated rainfall on development and survival of the spruce spider mite (Oligonychus 357 ununguis). Can. Entomol. 115: 93-105.

358 Dittrich, V. 1971. Electron-microscopic studies of the respiratory mechanism of spider mite eggs. 359 Ann. Entomol. Soc. Am. 64: 1134-1143.

360 Duso, C., F. Chiarini, L. Conte, V. Bonora, L. D. Montà, and S. Otto. 2004. Fogging can 361 control Tetranychus urticae on greenhouse cucumbers. J. Pest Sci. 77: 105-111.

362 Ferro, D. N., and R. B. Chapman. 1979. Effects of different constant humidities and 363 temperatures on twospotted spider mite egg hatch. Environ. Entomol. 8: 701-705. 
364 Foott, W. H. 1963. Competition between two species of mites. II. Factors influencing intensity. $365 \quad$ Can. Entomol. 95: 45-57.

366 Fukaya, M., R. Uesugi, H. Ohashi, Y. Sakai, M. Sudo, A. Kasai, H. Kishimoto, and M.

367 Osakabe. 2013. Tolerance to solar ultraviolet-B radiation in the citrus red mite, an upper 368 surface user of host plant leaves. Photochem. Photobiol. 89: 424-431.

369 Gerson, U. 1985. Webbing, pp. 223-232. In W. Helle and M. W. Sabelis (eds.), Spider mites.

370 Their biology, natural enemies, and control, vol. 1A. Elsevier, New York, NY.

371 Herne, D. H. C. 1968. Some responses of the European red mite, Panonychus ulmi, to immersion 372 in water. Can. Entomol. 100: 540-541.

373 Ho, C. 2000. Spider-mite problems and control in Taiwan. Exp. Appl. Acarol. 24: 453-462.

374 Ikegami, Y., S. Yano, J. Takabayashi, and A. Takafuji. 2000. Function of quiescence of

375 Tetranychus kanzawai (Acari: Tetranychidae), as a defense mechanism against rain. Appl.

$376 \quad$ Entomol. Zool. 35: 339-343.

377

378

379

380

Jones, V. P., and M. P. Parrella. 1984. Intratree regression sampling plans for the citrus red mite (Acari: Tetranychidae) on lemons in southern California. J. Econ. Entomol. 77: 810-813.

Kato, T. 1972. Seasonal behavior of citrus red mite, Panonychus citri (McGregor), in a leaf of citrus tree. Jpn. J. Appl. Entomol. Zool. 16: 154-156.

Kitashima, Y., and T. Gotoh. 1995. Host range difference and reproductive incompatibility among five populations of the citrus red mite, Panonychus citri (McGregor) (Acari: Tetranychidae). J. Acarol. Soc. Jpn. 4: 91-101. 
384 Klubertanz, T. H., L. P. Pedigo, and R. E. Carlson. 1990. Effects of plant moisture stress and 385 rainfall on population dynamics of the twospotted spider mite (Acari: Tetranychidae). Environ. 386 Entomol. 19: 1773-1779.

Kuenen, D. J. 1946. Het winterei van het Fruitspint (Metatetranychus ulmi Koch) en zijn bestrijding. Tijdschrift over Plantenziekten 52: 69-82.

Lu, F., Q. Chen, Z. Chen, H. Lu, X. Xu, and F. Jing. 2014. Effects of heat stress on development, reproduction and activities of protective enzymes in Mononychellus mcgregori. Exp. Appl. Acarol. 63: 267-284.

McEnro, W. E. 1961. The control of water loss by the twospotted spider mite (Tetranychus telarius). Ann. Entomol. Soc. Am. 54: 883-887.

Mori, H. 1957. The influence of temperature and relative humidity upon the development of the eggs of fruit tree red spider mite Metatetranychus ulmi (Koch) (Acarina: Tetranychidae). J. Fac. Agric. Hokkaido Univ. 50: 363-370.

Moriyama, M., and H. Numata. 2006. Induction of egg hatching by high humidity in the cicada Cryptotympana facialis. J. Insect Physiol. 52: 1219-1225.

Oku, K., S. Yano, and A. Takafuji. 2006. Host plant acceptance by the phytophagous mite Tetranychus kanzawai Kishida is affected by the availability of a refuge on the leaf surface.

402 Osakabe, M. 1959. Ecological study on the tea red spider mite (Tetranychus kanzawai Kishida) 403 (Part 4) The influence of temperature and relative humidity upon the development of the egg. 404 Tea Res. J. 13: 53-57. 
405 Osakabe, M. 1965. Seasonal fluctuation of population density of the tea red spider mite,

406 Tetranychus kanzawai Kishida, in the tea plantation. Jpn. J. Appl. Entomol. Zool. 9: 206-210.

407 Osakabe, M. 1967. Biological studies on the tea red spider mite, Tetranychus kanzawai Kishida, 408 in tea plantation. Bull. Tea Res. Sta. 4: 35-156.

409 Osakabe, M. 1987. Esterase activities and developmental success of the citrus red mite,

410 Panonychus citri (McGregor) (Acarina: Tetranychidae), on several plants. Appl. Entomol.

411 Zool. 22: 35-44.

412 Osakabe, M., K. Hongo, K. Funayama, and S. Osumi. 2006. Amensalism via webs causes

413 unidirectional shifts of dominance in spider mite communities. Oecologia 150: 496-505.

414 Perring, T. M., T. O. Holtzer, J. A. Kalisch, and J. M. Norman. 1984. Temperature and

415 humidity effects on ovipositional rates, fecundity, and longevity of adult females Banks grass

416 mites (Acari: Tetranychidae). Ann. Entomol. Soc. Am. 77: 581-586.

417 Peters, K. M., and R. E. Berry. 1980. Effect of hop leaf morphology on twospotted spider mite. J.

$418 \quad$ Econ. Entomol. 73: 235-238.

419 Pickford, R. 1960. Survival, fecundity, and population growth of Melanoplus bilituratus (Wlk.)

420 (Orthoptera: Acrididae) in relation to date of hatching. Can. Entomol. 92: 1-10.

421 Putman, W. L. 1968. Some effects of anoxia and hypoxia on the European red mite, Panonychus 422 ulmi (Acarina: Tetranychidae). Can. Entomol. 100: 617-623.

423 Putman, W. L. 1970. Effects of water and high humidity on the European red mite, Panonychus 424 ulmi (Acarina: Tetranychidae). Can. Entomol. 102: 955-961. 
425 R Core Development Team. 2012. R: a language and environment for statistical computing. $R$

426 Foundation for Statistical Computing. (http://www.lsw.uni-

427 heidelberg.de/users/christlieb/teaching/UKStaSS10/R-refman.pdf).

428 Rêgo, A. S., A. V. Teodoro, A. G. S. Maciel, and R. A. Sarmento. 2013. Relative contribution

429 of biotic and abiotic factors to the population density of the cassava green mite,

430 Mononychellus tanajoa (Acari: Tetranychidae). Exp. Appl. Acarol. 60: 479-484.

431 Sakai, Y., M. Sudo, and M. Osakabe. 2012. Seasonal changes in the deleterious effects of solar

432 ultraviolet-B radiation on eggs of the twospotted spider mite, Tetranychus urticae (Acari:

433 Tetranychidae). Appl. Entomol. Zool. 47: 67-73.

434 Sokal, R. R., and F. J. Rohlf. 2000. Biometry, 3rd ed. Freeman, New York, NY.

435 Sudo, M., and M. Osakabe. 2011. Do plant mites commonly prefer the underside of leaves? Exp.

$436 \quad$ Appl. Acarol. 55: 25-38.

437 


\section{Figure Captions}

439

440 Fig. 1. Experimental design for testing the effects of submergence in water on egg hatch timing.

Fig. 2. Effects of high humidity treatments from immediately after oviposition to hatching on egg hatch timing (Exp-1). Solid circles and open triangles represent high humidity and control treatments, respectively. Open circles show the hatch rates after lids of Petri dishes were opened and humidity began decreasing. Vertical lines on plots represent $95 \%$ fiducial limits.

Fig. 3. Effects of high humidity immediately before hatching was due on egg hatch timing (Exp-2). Solid circles and open triangles represent high humidity and control treatments, respectively. Open circles show the hatch rate after lids of Petri dishes were opened and humidity began decreasing. Vertical lines on plots represent $95 \%$ fiducial limits.

Fig. 4. Effects of high humidity implemented immediately after oviposition and continuously after hatching was due on egg hatch timing (Exp-3). Solid circles and open triangles represent high humidity and control treatments, respectively. Vertical lines on plots represent 95\% fiducial limits.

460 Fig. 5. Effects of submergence in water from (a) immediately after oviposition to hatching (Exp-4) and (b) immediately before hatching was due (Exp-5). Solid circles and open 
triangles represent submergence and control treatments, respectively. Open circles fiducial limits. 


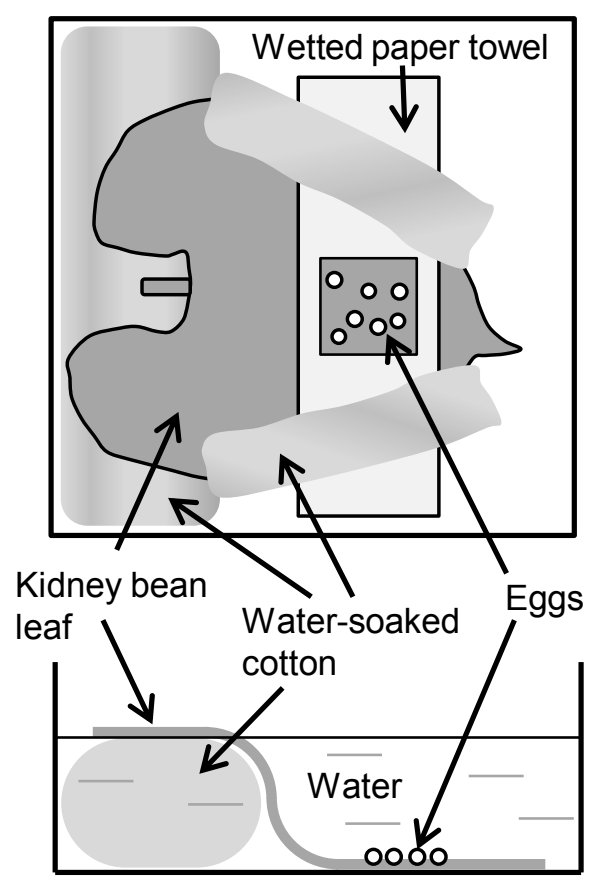

Fig. 1 
Tetranychus

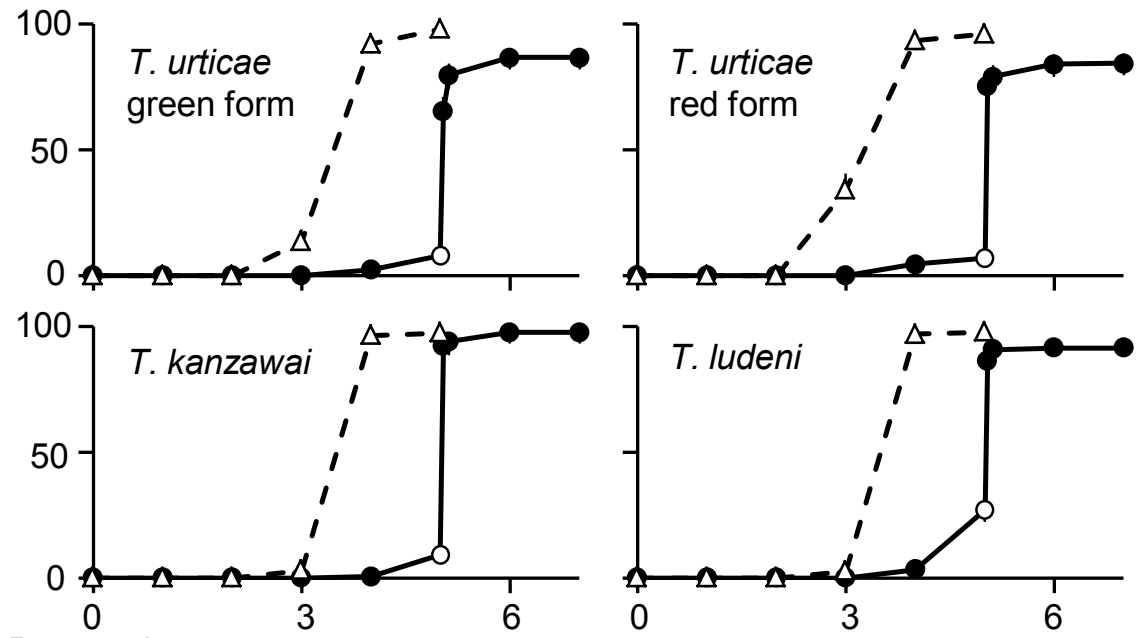

Panonychus

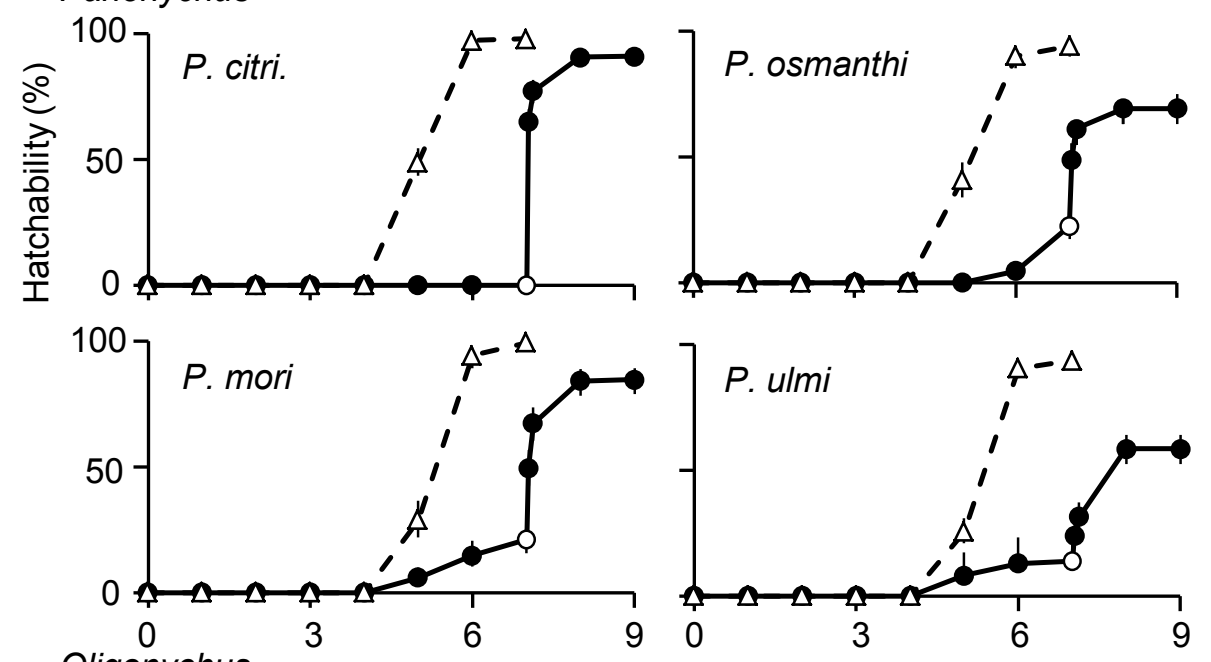

Oligonychus

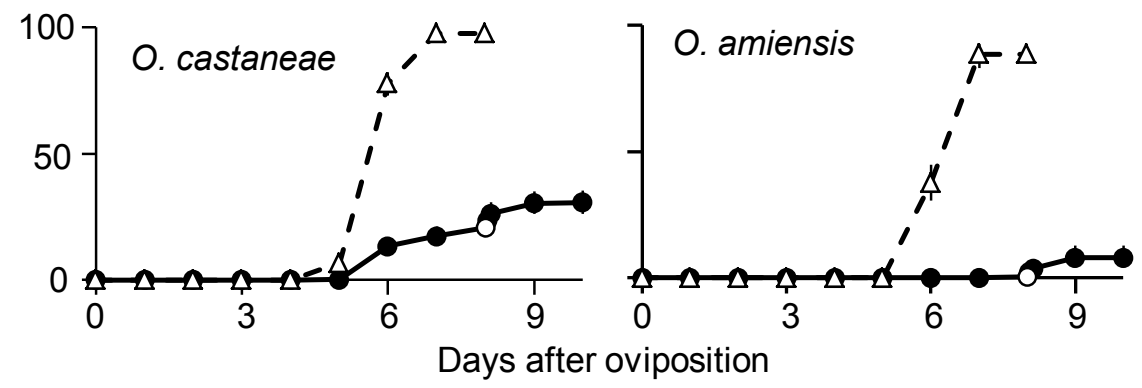

Fig. 2 
Tetranychus

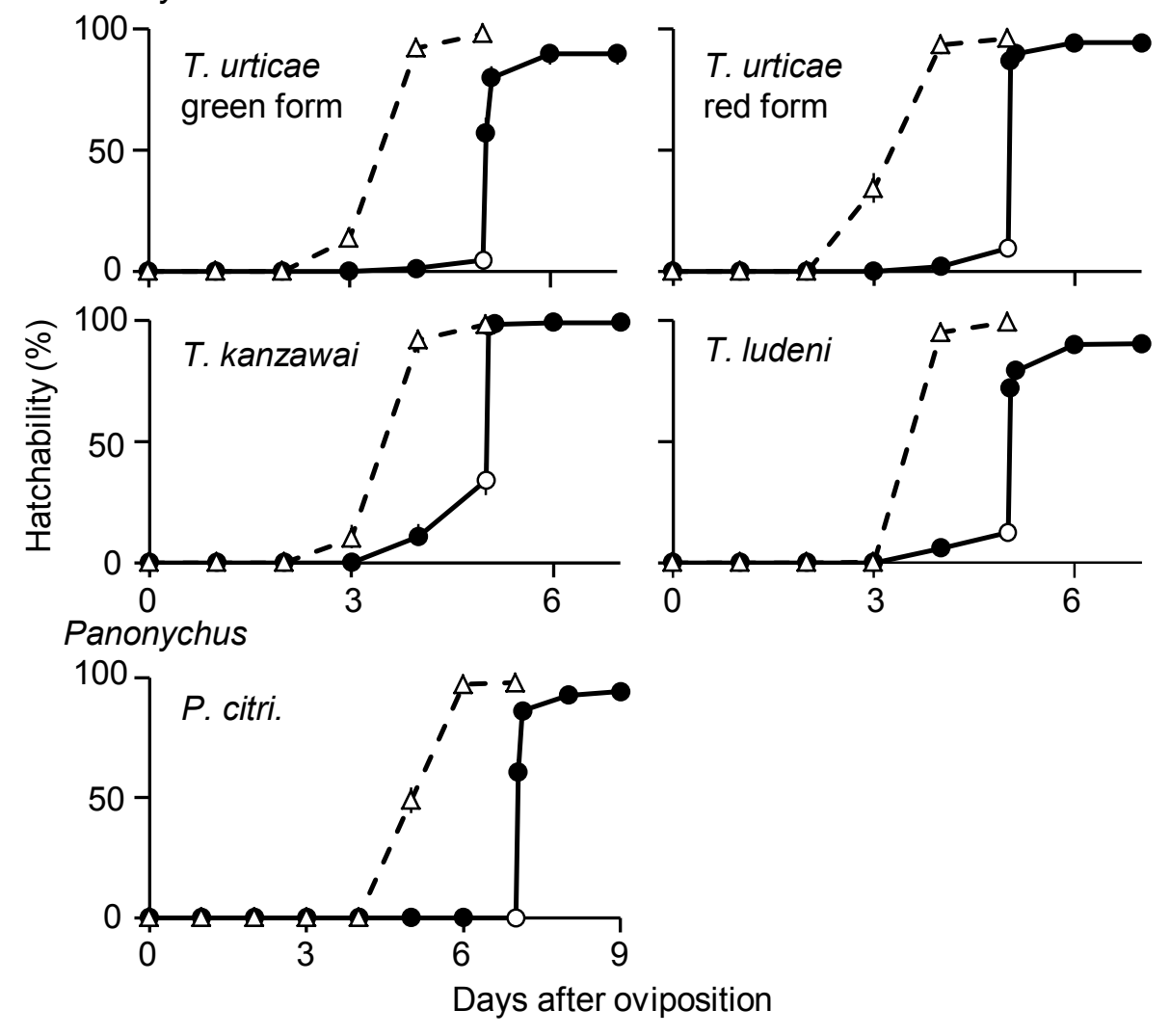

Fig. 3 


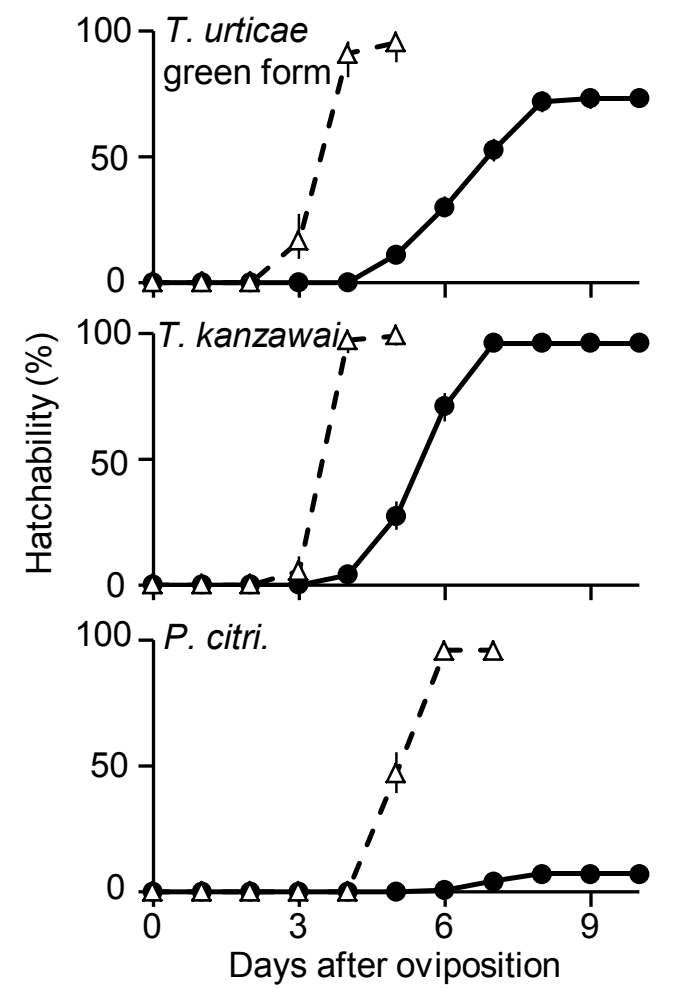

Fig. 4 
京都大学

Kyoto University Relf-archived copy in

A Self-archived copy in

ion Repository

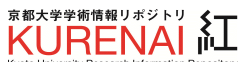

(a)

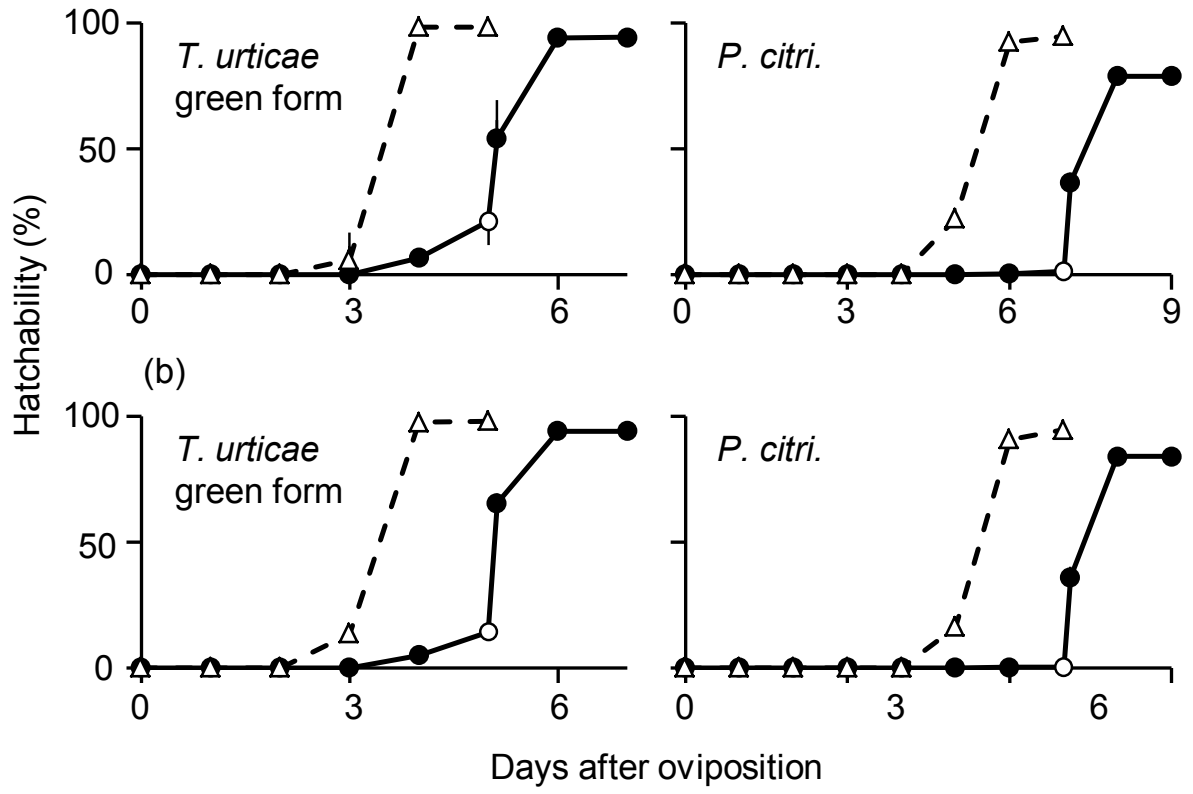

Fig. 5 
Table 1 Ranges in temperature and humidity in three types of experiments

\begin{tabular}{|c|c|c|c|c|}
\hline & \multicolumn{2}{|c|}{ Temperature $\pm \mathrm{SD}\left({ }^{\circ} \mathrm{C}\right)$} & \multicolumn{2}{|c|}{ Humidity \pm SD (\%) } \\
\hline & $\mathrm{HH}^{\mathrm{a}}$ & Cont $^{b}$ & $\mathrm{HH}^{\mathrm{a}}$ & Cont $^{b}$ \\
\hline \multicolumn{5}{|l|}{ Exp-1 } \\
\hline Minimum & $24.7 \pm 0.5$ & $23.9 \pm 0.3$ & $94.4 \pm 0.5$ & $81.3 \pm 2.7$ \\
\hline Maximum & $26.1 \pm 0.5$ & $25.7 \pm 0.5$ & $98.5 \pm 0.7$ & $92.4 \pm 2.7$ \\
\hline \multicolumn{5}{|l|}{ Exp-2 } \\
\hline Minimum & $24.8 \pm 0.5$ & $23.8 \pm 0.4$ & $94.4 \pm 0.7$ & $77.8 \pm 5.6$ \\
\hline Maximum & $25.7 \pm 0.6$ & $24.4 \pm 0.5$ & $97.8 \pm 0.5$ & $90.9 \pm 1.3$ \\
\hline \multicolumn{5}{|l|}{ Exp-3 } \\
\hline & $26.1 \pm 0.8$ & $24.9 \pm 0.4$ & $96.7 \pm 0.5$ & $85.1 \pm 5.4$ \\
\hline
\end{tabular}

${ }^{\text {a }}$ Averaged temperature during the dishes were covered with lids in the high humidity treatment in an experiment. For Exp-1 and Exp-2 we show only the cases of minimum and maximum averages over replications in the same experiment.

${ }^{\mathrm{b}}$ Average in the control treatment in an experiment. 
Table 2 Success for adjusting the hatch timing in high humidity treatments from immediately after oviposition to hatching (Exp-1)

\begin{tabular}{|c|c|c|c|c|c|}
\hline & Treatments & No. eggs ${ }^{a}$ & $\begin{array}{c}\text { Eye spots } \\
(\%)^{b}\end{array}$ & $\begin{array}{l}\text { Hatch rate } \\
\qquad(\%)^{c}\end{array}$ & $\begin{array}{l}\text { Hatch rate after } \\
\text { humidity } \\
\text { decreasing }(\%){ }^{d}\end{array}$ \\
\hline T. urticae & High humidity & 255 & 96.5 & $86.7 * * *$ & $78.8 \mathrm{~b}$ \\
\hline (green form) & Control & 264 & - & 98.1 & - \\
\hline T. urticae & High humidity & 262 & 93.9 & $84.4 * * *$ & $77.5 \mathrm{bc}$ \\
\hline (red form) & Control & 228 & - & 96.1 & - \\
\hline \multirow[t]{2}{*}{ T. kanzawai } & High humidity & 164 & 98.2 & $97.6 \mathrm{~ns}$ & $88.4 \mathrm{a}$ \\
\hline & Control & 195 & - & 97.4 & - \\
\hline \multirow[t]{2}{*}{ T. ludeni } & High humidity & 303 & 96.4 & $91.4 * *$ & $64.4 \mathrm{c}$ \\
\hline & Control & 224 & - & 97.8 & - \\
\hline \multirow[t]{2}{*}{ P. citri } & High humidity & 329 & 95.1 & $90.9 * * *$ & $90.9 \mathrm{a}$ \\
\hline & Control & 329 & - & 97.9 & - \\
\hline \multirow[t]{2}{*}{ P. osmanthi } & High humidity & 237 & 92.0 & $69.2 * * *$ & $46.8 \mathrm{de}$ \\
\hline & Control & 201 & - & 94.0 & - \\
\hline \multirow[t]{2}{*}{ P. mori } & High humidity & 202 & 96.5 & $84.6 * * *$ & $63.4 \mathrm{~cd}$ \\
\hline & Control & 156 & - & 99.4 & - \\
\hline \multirow[t]{2}{*}{ P. ulmi } & High humidity & 279 & 94.6 & $58.4 * * *$ & $44.4 \mathrm{e}$ \\
\hline & Control & 293 & - & 93.5 & - \\
\hline \multirow[t]{2}{*}{ O. castaneae } & High humidity & 428 & 93.5 & $30.6 * * *$ & $9.8 \mathrm{f}$ \\
\hline & Control & 320 & - & 97.5 & - \\
\hline \multirow[t]{2}{*}{ O. amiensis } & High humidity & 191 & 89.5 & $7.9 * * *$ & $7.3 \mathrm{f}$ \\
\hline & Control & 184 & - & 88.6 & - \\
\hline
\end{tabular}

\footnotetext{
${ }^{\mathrm{a}}$ The sum total of eggs used in experiments three times.

${ }^{\mathrm{b}}$ Percentages of eggs in which red eye spots were developed.

${ }^{\mathrm{c}}$ Hatch rate in total over experimental periods. Triple, double, and single asterisks at high humidity indicate $P$-values against control to be $<0.001,<0.01$, and $<0.05$, respectively, by Fisher's exact test.

${ }^{d}$ Percentage of eggs which hatched after lids of Petri dishes were opened and humidity decreased. The same letter in the column represent that no significant differences were detected among species by an $R \times C$ test of independence using a $G$-test $(P>0.05)$.
} 
Table 3 Success for adjusting the hatch timing in high humidity treatments from immediately before hatching was due (Exp-2)

\begin{tabular}{|c|c|c|c|c|}
\hline & Treatments & No. eggs ${ }^{a}$ & $\begin{array}{l}\text { Hatch rate } \\
\qquad(\%)^{c}\end{array}$ & $\begin{array}{l}\text { Hatch rate after } \\
\text { humidity } \\
\text { decreasing }(\%)\end{array}$ \\
\hline T. urticae & High humidity & 243 & $89.7 * * *$ & $85.1 \mathrm{~b}$ \\
\hline (green form) & Control & 264 & 98.1 & - \\
\hline T. urticae & High humidity & 294 & $94.2 \mathrm{~ns}$ & $84.7 \mathrm{~b}$ \\
\hline (red form) & Control & 228 & 96.1 & - \\
\hline \multirow[t]{2}{*}{ T. kanzawai } & High humidity & 193 & $99.0 \mathrm{~ns}$ & $64.7 \mathrm{c}$ \\
\hline & Control & 161 & 98.1 & - \\
\hline \multirow[t]{2}{*}{ T. ludeni } & High humidity & 494 & $90.3 * * *$ & $77.7 \mathrm{~b}$ \\
\hline & Control & 352 & 99.1 & - \\
\hline \multirow[t]{2}{*}{ P. citri } & High humidity & 326 & $94.2 *$ & $94.2 \mathrm{a}$ \\
\hline & Control & 329 & 97.9 & - \\
\hline
\end{tabular}

${ }^{\text {a }}$ The sum total of eggs used in experiments three times.

${ }^{b}$ Percentages of eggs in which red eye spots were developed.

${ }^{\mathrm{c}}$ Hatchability in total over experimental periods. About asterisks see Table 1.

${ }^{\mathrm{d}}$ Percentage of eggs which hatched after lids were opened and humidity decreased. The same letters in the column represent that no significant difference was detected in unplanned tests of homogeneity $(P>0.05)$ after an $R \times C$ test of independence using a $G$-test. 
Table 4 Success for adjusting the timing of hatching in submergence treatments from (a) immediately after oviposition to hatching (Exp-4) and (b) immediately before hatching was due $(\operatorname{Exp}-5)(\mathrm{b})$

\begin{tabular}{|c|c|c|c|c|c|}
\hline & Treatments & No. eggs ${ }^{a}$ & $\begin{array}{c}\text { Eye spots } \\
(\%)^{b}\end{array}$ & $\begin{array}{c}\text { Hatchability } \\
(\%)^{c}\end{array}$ & $\begin{array}{c}\text { Hatch rate after } \\
\text { drained (\%) }\end{array}$ \\
\hline \multicolumn{6}{|l|}{ (a) } \\
\hline T. urticae & Submergence & 642 & 97.4 & $94.2 * * *$ & $73.1 \mathrm{~ns}$ \\
\hline (green form) & Control & 554 & - & 98.4 & - \\
\hline \multirow[t]{2}{*}{ P. citri } & Submergence & 585 & 97.1 & $78.8 * * *$ & 77.6 \\
\hline & \multicolumn{5}{|c|}{ (b) } \\
\hline T. urticae & Submergence & 578 & - & $94.1 * * *$ & $79.8 \mathrm{~ns}$ \\
\hline (green form) & Control & 563 & - & 98.0 & - \\
\hline \multirow[t]{2}{*}{ P. citri } & Submergence & 556 & - & $84.0 * * *$ & 83.6 \\
\hline & Control & 463 & - & 94.6 & - \\
\hline
\end{tabular}

${ }^{\mathrm{a}}$ The sum total of eggs used in experiments three times.

${ }^{\mathrm{b}}$ Percentages of eggs in which red eye spots were developed. No significant differences were detected among species by an $R \times C$ test of independence using a $G$-test $(P>0.05)$.

${ }^{\mathrm{c}}$ Hatchability in total over experimental periods. About asterisks see Table 1.

${ }^{\mathrm{d}}$ Percentage of eggs which hatched after the humidity declined (lids were opened). No significant differences were detected among species by an $R \times C$ test of independence using a $G$-test $(P>$ $0.05)$. 
Table 5 Effects of high humidity and submergence treatments on subsequent development and egg production (Exp-6)

\begin{tabular}{|c|c|c|c|c|c|}
\hline & & & High humidity & Submergence & Control \\
\hline \multirow{5}{*}{$\begin{array}{l}\text { T. urticae } \\
\text { green form }\end{array}$} & Development (\%) ${ }^{\mathrm{a}}$ & & $89.4(170) \mathrm{ab}$ & $86.2(159) \mathrm{b}$ & $94.1(222) \mathrm{a}$ \\
\hline & Sex ratio $q /\left(q+{ }^{\lambda}\right)^{b}$ & & $0.82(152)$ & $0.82(137)$ & $0.86(209) \mathrm{ns}$ \\
\hline & Developmental & 우 & $6.5 \pm 0.1(48) a$ & $6.4 \pm 0.1(38) \mathrm{a}$ & $6.1 \pm 0.1(44) b$ \\
\hline & duration $^{c}$ & $0^{\lambda}$ & $6.1 \pm 0.1(9)$ & $6.1 \pm 0.1(10)$ & $6.1 \pm 0.1(14) \mathrm{ns}$ \\
\hline & Egg production ${ }^{\mathrm{d}}$ & & $47.2 \pm 0.7(43)$ & $47.8 \pm 1.0(34)$ & $49.2 \pm 1.2(38) \mathrm{ns}$ \\
\hline \multirow[t]{5}{*}{ P. citri } & Development $(\%)^{\mathrm{a}}$ & & $94.4(180) \mathrm{ab}$ & $87.9(149) b$ & $95.5(179) \mathrm{a}$ \\
\hline & Sex ratio $q /(q+\pi)^{\mathrm{b}}$ & & $0.81(170)$ & $0.88(149)$ & $0.83(171) \mathrm{ns}$ \\
\hline & Developmental & o & $6.7 \pm 0.1(43)$ & $6.8 \pm 0.1(41)$ & $6.5 \pm 0.1(45) \mathrm{ns}$ \\
\hline & duration $^{c}$ & $0^{1}$ & $6.9 \pm 0.1(9)$ & $6.9 \pm 0.1(8)$ & $6.5 \pm 0.2(10) \mathrm{ns}$ \\
\hline & Egg production ${ }^{\mathrm{d}}$ & & $19.6 \pm 0.7(36)$ & $19.2 \pm 0.6(34)$ & $19.8 \pm 0.6(38) \mathrm{ns}$ \\
\hline
\end{tabular}

Figures of parentheses represent the numbers of individuals tested.

${ }^{a}$ Developmental success from larva to adult. The same letters in the column represent that no significant difference was detected in unplanned tests of homogeneity $(P>0.05)$ after an $R \times C$ test of independence using a $G$-test.

${ }^{\mathrm{b}}$ Sex ratio in individuals which developed to adulthood. No significant differences were detected among species by an $R \times C$ test of independence using a $G$-test $(P>0.05)$.

${ }^{\mathrm{c}}$ Developmental times from larva to adult. The same letters in the line for T. urticae females were not significantly different at a 5\% level in multiple comparisons using Tukey HSD. No significant differences were detected by a one-way ANOVA in T. urticae male and P. citri.

${ }^{d}$ Number of eggs laid for the first five oviposition days. No significant differences were detected among treatments in both species by Wald tests using GLM. 